\title{
A BUSCA DE INFORMAÇÃO NA WEB: DOS PROBLEMAS DO LEITOR ÀS PRÁTICAS DE ENSINO
}

Iúta Lerche Vieira*

\begin{abstract}
Resumo: O ensaio discute a busca de informação, tipo preferencial de leitura na Web, a partir de dados de uma pesquisa mais ampla (VIEIRA, 2007a), aqui analisados sob o ângulo do leitor e da aplicação escolar. A discussão situa-se no contexto da explosão informativa provocada pela Internet e dos desafios da escola, onde a pesquisa de informações sempre foi um problema mal resolvido. A busca de informação é vista de acordo com uma tipologia de dificuldades de leitura na Web. Os dados analisados revelam uma grande divergência entre as necessidades ou práticas do leitor virtual e as propostas de ensino mais frequentes, mostrando que, embora a pesquisa informativa na rede constitua o maior problema dos leitores, inversamente é a atividade leitora menos focalizada e trabalhada na escola. Por fim, questiona-se o modo como se pode ensinar a buscar informação na Internet, apontando-se algumas estratégias.
\end{abstract}

Palavras-chave: letramento digital; leitura na internet; busca de informação; leitura crítica; pesquisa escolar.

\section{INTRODUÇÃO' ${ }^{1}$}

A Internet desempenha três grandes funções: pesquisa, comunicação e publicação (PORTAL, 2007). Neste texto, refletimos sobre a primeira delas - a pesquisa de informação - esta habilidade tão necessária ao leitor e relegada na escola, que é o "feijão-com-arroz" da Internet. Embora outras habilidades leitoras continuem sendo

\footnotetext{
* Professora da Universidade Estadual do Ceará, Fortaleza, Ceará, Brasil. Doutora em Linguística. Email: <iutalerche@gmail.com>.

${ }^{1}$ As idéias aqui reunidas foram apresentadas originalmente na Mesa-Redonda "Letramento Digital e Ensino", no II Encontro Nacional de Hipertexto, UFC/UFPE, Fortaleza, 25 a 27/10/2007.
} 
necessárias, buscar, selecionar e avaliar informação na Web 2 tornaram-se práticas supervalorizadas nos novos modos de ler, influenciando igualmente o modo de escrever na/para a tela. Hoje, mais do que nunca, é essencial selecionar bem a informação, sabendo distinguir sua procedência, qualidade e adequação aos propósitos do usuário.

A atividade de pesquisa escolar, por sua vez, precisa ser contextualizada e rediscutida no ensino/aprendizagem mediado por computador. O termo veio do latim ("perquisitum") e nos chegou através do espanhol ("perquiro"), significando: procurar, buscar com cuidado, informar-se, aprofundar a busca (BAGNO, 1998, apud BERNARDES; FERNANDES, 2005). Na escola brasileira, segundo esses mesmos autores (2005), a expressão entrou por decreto oficial e virou prática obrigatória através da lei 5692/1971. De lá para cá, em quase quatro décadas de existência, a pesquisa escolar foi sempre uma atividade problemática, seja no papel ou na tela. Atividade rotineira, mecânica, enfrentando problemas de integração entre áreas de ensino e de biblioteca, ela tem como um de seus principais desafios resolver o conflito "copiar/construir conhecimento", transposto para a Internet na versão "copiar/colar".

Com a tecnologia do computador e a Internet, como se situa agora a busca e a pesquisa de informação? Esta é a questão central de nossa reflexão.

\footnotetext{
${ }^{2}$ Web (www) é abreviatura de World Wide Web (teia de aranha mundial). É frequente o uso do termo "Internet" pelo de "Web", contudo os dois termos referem-se a conceitos diferentes: a Internet pode ser entendida como a tecnologia que permite estabelecer uma rede de milhares de redes de computadores e representa a infraestrutura de conexão dessas redes; a Web é a rede de comunicação que mais se popularizou, onde acessamos portais e websites. É, pois, uma aplicação dentro da Internet, um subprotocolo nela contido, uma maneira ou modelo de compartilhamento de informação dos computadores que estão nessa rede, da mesma forma como o são, por exemplo, o e-mail e o MSN. Neste texto, priorizamos o termo Web, tecnicamente mais adequado. Ao usarmos o termo consensual "Internet", o faremos com o mesmo sentido de Web, ou rede virtual de compartilhamento de informações.
}

VIEIRA - A busca de informação na web... 


\section{QUESTIONAMENTOS E REFERENCIAL TEÓRICO}

\section{a) Explosão informativa na Web: um "dilúvio de informação" (ECO, 2000)}

$\mathrm{Na}$ sociedade global em rede o poder está na informação, não mais na terra, no trabalho, nem mesmo no capital. Hoje a informação nos invade por todos os lados, em diferentes meios, suportes e mídias: internet, livros, jornais, revistas, panfletos, publicidade, outdoors, televisão, cinema, vídeo, escola, trabalho, meio acadêmico etc. Umberto Eco (2000, p. 11-15) diz que a Internet "é como uma enchente e não há como parar a invasão de informação". Para o autor, esse excesso de informação tende a tornar-se prejudicial e "equivale ao puro silêncio".

Em 2003 já existiam mais de dois bilhões de sites na Internet, embora menos da quarta parte deles estivesse coberta pelos portais de busca (dados do SEARCH ENGINE WATCH, 2003). Para se ter uma ideia do volume de informação circulante, hoje uma única edição semanal do New York Times contém mais informação que a média de pessoas na Inglaterra do século XVII adquiria em sua vida inteira. Estima-se também que nos últimos 30 anos tenha sido produzida mais informação do que nos 5000 anos anteriores (WURMAN, 1989, apud JUNGWIRTH; BRUCE, 2002, p. 400). Estatísticas como estas ressaltam o fenômeno da explosão de informação e a consequente sobrecarga informativa. Como decorrência, surge uma nova forma de stress - a ansiedade informativa - cuja prevenção estaria no controle da informação. Não se trata de censura, mas de discernimento e crítica, indispensáveis aos novos usos sociais da escrita para quem queira se tornar letrado nesta sociedade em rede, através da comunicação visual e eletrônica.

\section{b) Leitura na Internet: (des)controle da quantidade/qualidade da informação}

Resultados de pesquisa recente sobre aplicações escolares da leitura na Internet (VIEIRA, 2007b) mostram que as vertentes mais exploradas no ensino da leitura e do letramento digital na realidade brasileira são: a exploração de recursos/gêneros da Internet (o foco mais 
frequente, 39\%); o desenvolvimento do letramento crítico (24\%); a transferência de habilidades da leitura impressa para leitura na tela (21\%); e as habilidades de busca da informação (16\%), estas, sem dúvida, o foco mais importante, embora tenham se revelado o menos frequente, na prática escolar. No presente estudo nós o aprofundaremos, buscando uma melhor compreensão da problemática da busca de informação na Web.

No "dilúvio de informação" em que estamos mergulhados (ECO, 2000) é urgente saber como distinguir a informação de qualidade. Como encontrar aquela que é útil e consistente? Como escapar do assédio da inutilidade? Da informação repetitiva, dispersa e não confiável? Como resistir à tentação e à curiosidade que nos rouba o tempo na Internet? Afinal, "como separar o joio do trigo"? E no âmbito escolar? Como enfrentar esses problemas de ordem tecnológica, como desenvolver habilidades de busca e de pesquisa? Que possibilidades e desafios ela encerra? Como lidar com isso em termos de leitura informativa e seletiva?

Tentaremos agregar elementos a essa reflexão, visando ATINGIR os seguintes objetivos:

- Situar a busca de informação - tipo preferencial de leitura na Weba partir de resultados de pesquisas, sob o ângulo do leitor e do ensino;

- Mostrar que a busca de informação é um problema recorrente entre as dificuldades gerais dos leitores;

- Discutir como desenvolver a habilidade de busca de informação na Web.

\section{METODOLOGIA}

Neste trabalho situamos a busca de informação sob o ângulo do leitor (usuário da Web) e sob o ângulo do ensino. Para tanto, fizemos uma reinterpretação detalhada de resultados de pesquisas, a partir de um recorte dos dados, procurando analisar mais detidamente tudo o que se referia à busca de informação na rede. 
Para observar a perspectiva do leitor, tomamos como referência dados de um estudo anterior de grande porte (VIEIRA, 2007a). A referida investigação tomou como corpus de análise dados de 180 informantes da comunidade escolar/universitária de Fortaleza/Ceará, dos 3 níveis de ensino, coletados em novembro/dezembro de 2003, sendo 155 alunos e 25 professores. A amostra de alunos foi composta de sujeitos do Ensino Fundamental ( $7^{\mathrm{a}}$. e $8^{\mathrm{a}}$. séries), Ensino Médio $\left(1^{\circ}\right.$. e $\left.2^{\circ}\right)$ e Ensino Superior (1 ${ }^{\circ}$. Ano da UECE). Os professores (25), representando 14\% da amostra, são de várias universidades de Fortaleza. O levantamento foi feito através de um questionário com 16 questões fechadas e 6 abertas. O estudo traça um perfil do leitor virtual, a partir da investigação de suas práticas e problemas na leitura do hipertexto e dos desafios para o ensino da leitura na web (referidos pelos informantes).

Para examinar a questão sob o ponto de vista da aplicação escolar, usamos dados de Vieira (2007b), complementados com opiniões de professores extraídas de um fórum no portal EducaRede em que discutiam o tema "Internet no ensino e pesquisa". (<www.educarede.org.br>, acesso em 7/10/2007 - ver Anexos 1 e 2).

O primeiro bloco desses dados refere-se a uma ampla pesquisa bibliográfica realizada, com análise de conteúdo de 38 artigos de pesquisa. $\mathrm{O}$ estudo explora o trabalho docente com letramento digital e leitura na Web, levantando o que vinha sendo realizado na área no período 20042005, com destaque para o ensino da leitura informativa. Investiga a aplicação escolar em fase inicial no Brasil e mais sedimentada em países onde a Internet já foi incorporada à prática escolar.

A segunda parte da análise sobre a aplicação escolar da leitura informativa na Web constou da observação de um fórum do portal EducaRede, acompanhado pela pesquisadora durante 3 dias, utilizando como dados mensagens de 24 participantes da discussão. Estas postagens foram recuperadas e ordenadas, sendo analisadas como complemento aos dados aqui pareados. Para acompanhar a discussão, a pesquisadora ordenou as mensagens por datas (de 1/10/07 em diante) e por horários de recebimento no fórum, listando-as "de trás para adiante", de modo a recuperar a linearidade da troca de ideias, perdida na configuração do portal, que vai arquivando as mensagens do fórum em ordem decrescente - as mais recentes em cima, ou "na frente" (na perspectiva da produção da mensagem e não de sua leitura). 


\section{RESULTADOS DE PESQUISAS SOBRE BUSCA DE INFORMAÇÃO NA WEB}

Para permitir uma melhor visualização, apresentamos em paralelo resultados selecionados de dois estudos sobre leitura na Internet: do lado esquerdo um levantamento com informantes brasileiros (VIEIRA, 2007a), do lado direito um levantamento bibliográfico de relatos de pesquisa envolvendo aplicações escolares da leitura na Internet em vários países, incluindo o Brasil (VIEIRA, 2007b). Mais exatamente: do lado esquerdo está disposto o que se refere ao sujeito leitor; do lado direito, o que diz respeito à escola. Observem que os resultados são opostos e divergentes: enquanto, do ponto de vista do leitor, para a grande maioria a busca de informação na Internet é uma realidade concreta, na escola ela é o foco menos importante no ensino da leitura e/ou do letramento digital.

\section{Leitor $(+)$}

- $84 \%$ dos informantes pesquisam na Internet

- A maioria faz busca rápida para aplicações práticas.

\section{PERFIS DE LEITORES}

- 62\% - leitor-usuário (maioria em todos os estratos da amostra)

- $25 \%$ - leitor-telespectador (+ jovens)

- $13 \%$ - leitor-leitor (universitários/professores)

\section{Escola (-)}

- Busca de informação é o foco temático menos contemplado pela escola (no corpus analisado)

\section{FOCOS TEMÁTICOS}

- $39 \%$ - exploração recursos/gêneros Internet

- $24 \%$ - desenvolvimento do letramento crítico

- $21 \%$ - transferência de habilidades papel para a tela

- $16 \%$ - habilidades de busca da informação

Se compararmos, ainda, (no mesmo quadro) os perfis de leitores na Web com os focos temáticos em leitura/letramento digital explorados pela escola, a tendência permanece: altos percentuais para as práticas leitoras que envolvem pesquisa de informação ("leitor-usuário"), enquanto a habilidade de busca de informação é o foco temático menos frequente nas atividades escolares. 
Esta fraca atuação da escola no ensino de habilidades de busca/avaliação de informação é reforçada por outros dados recentes de professores, colhidos pela autora em observação informal de um fórum realizado no Portal EducaRede (acessado em 7/10/2007). Como podem ver no quadro seguinte, apenas $8 \%$ dos depoimentos dos participantes referem-se de fato à orientação para busca de informação. 17\% apontam a indicação de sites como meio de desenvolver habilidades de leitura seletiva. Assim, os depoimentos levantados mostram que, mesmo indagados diretamente sobre o ensino de habilidades de pesquisa, os professores revelam outras preocupações, como sua própria formação para atuar no meio digital.

\subsection{Opinião de professores no Fórum EducaRede "Internet e Ensino" www.educarede.org.br (7/10/07)}

Mediadora: "Como o professor pode desenvolver as habilidades de pesquisa de seus alunos? Ou será ele um eterno filtro entre o aluno e a Internet?"

Prioridades (reveladas em amostra de 24 trocas de mensagens):

- Formação e papel do professor - 50\%

- Inclusão digital ou adesão à Internet - 17\%

- Indicação de sites $-\mathbf{1 7 \%}$

- Planejamento c/ flexibilidade - 8\%

- Orientação específica para pesquisa - 8\%

Como sintetizam os dados acima, o levantamento quantitativo da amostra de mensagens acompanhadas em um fórum no Portal EducaRede (complemento à nossa análise) revela quanto os professores derivaram da pergunta central proposta pela mediadora sobre como desenvolver as habilidades de pesquisa dos alunos. Apenas em terceiro lugar entre os assuntos discutidos nas mensagens foi que surgiu a "indicação de sites" $(17 \%$ de ocorrências nos 3 dias de fórum observados).

No anexo 3, apresentamos um levantamento que resume as idéias dos participantes do fórum, através do qual observamos como os 
professores estavam percebendo a questão da pesquisa de informação na Web.

\subsection{A busca de informação entre os problemas gerais para ler na Web}

Nos próximos blocos de dados, mostramos como se situa a busca de informação, entre as dificuldades do leitor virtual. Os dados (coletados em 2004) nos permitem situar a leitura seletiva na Web em uma tipologia de dificuldades leitoras. Este primeiro conjunto de dados retrata os problemas de leitura online apontados pelos leitores por blocos de dificuldades, dando ao professor um quadro de referência comparativo. Observem que a tarefa de localizar e selecionar informação na Web é vista pelo usuário da Internet como uma dificuldade geral quase tão frequente quanto a que foi apontada em primeiro lugar:

- 35\% - navegação na Internet/movimentação no site (tipo 1)

- 33\% localização e seleção da informação (tipo 2)

- 14\% monitoramento da leitura (habilidades metacognitivas tipo 3)

- $14 \%$ não especificaram o tipo de dificuldade

- 4\% não têm dificuldade

A seguir, vejam como se apresenta a questão da busca de informação na Web (em negrito), a partir do detalhamento de cada bloco de dificuldades leitoras. Observem, ainda, como as demais dificuldades apontadas também estão relacionadas à busca de informação:

\section{Tipo 1 - navegação e/ou movimentação no site}

- 33\% problemas técnicos p/ conexão ou acesso à Internet

- $\mathbf{3 2 \%}$ cansaço p/ ler "rolando" a tela ou posição 
- 19\% visualmente confusos c/organização gráfica do site

- $16 \%$ dificuldade em localizar informações pelo nome dos links

O segundo bloco de problemas de leitura na web trata especificamente da habilidade para pesquisar informações na rede. Aqui podemos ver em detalhe quantos e quais problemas o leitor enfrenta neste tipo de leitura seletiva:

\section{Tipo 2 - localização ou seleção da informação}

- 35\% perdidos ou stress cognitivo pelo excesso de informação

- $25 \%$ gastam tempo pela dispersão de informações

- $24 \%$ dificuldade em escolher palavras-chave para campos de busca

- 16\% não sabem identificar a informação mais importante, nem em que sequência ler

O terceiro bloco de dificuldades aprofunda a questão, na medida em que revela as habilidades metacognitivas do leitor direcionadas ao problema de leitura mais grave na web. Vejam como cada uma destas dificuldades está diretamente implicada no problema de pesquisar informação na rede. $\mathrm{O}$ conhecimento desta tipologia alerta o professor sobre a necessidade de trabalhar mais diretamente com o ensino da leitura seletiva na Internet.

\section{Tipo 3 - controle ou monitoramento da própria leitura}

- $28 \%$ se dispersam e não conseguem manter o tópico de interesse ou propósitos iniciais

- $27 \%$ têm problemas em relacionar informações e chegar a uma conclusão

- 23\% não sabem reunir as informações de maneira lógica (mesmo com consciência dos links percorridos)

- $22 \%$ têm dificuldade em saber onde parar a busca 


\section{CONSIDERAÇÕES FINAIS: ENSINANDO A BUSCAR INFORMAÇÃO NA INTERNET}

A seguir, traçamos algumas coordenadas para o trabalho pedagógico com busca de informação. Em primeiro lugar, é recomendável abordar o processo de pesquisar, ao invés de focalizar apenas os resultados da pesquisa. Henry (2006) considera que os professores podem ajudar os estudantes a serem pesquisadores mais bem sucedidos oferecendo-lhes oportunidades para praticar a pesquisa de informação e analisando resultados de sites de busca para melhor compreender o processo de pesquisar. Seguem algumas sugestões a respeito (VIEIRA, 2007b; HENRY, 2006):

- Para que pesquisar? Estabelecer um propósito (projetos/ situações-problema, temas específicos em áreas de conteúdo);

- Dar instruções prévias;

- Limites da busca: foco e tempo;

- Discutir problemas de busca: o computador não "entende" tudo. Ensinar técnicas e sintaxe de busca (operadores bulianos: "e", "ou", "não", aspas);

- O quê pesquisar? Como? Delimitar o assunto (contexto da tarefa);

- Palavras-chave, vocabulário - termos genéricos/específicos;

- Onde pesquisar? Compartilhar sites, portais; indicar endereços;

- Avaliar websites: fontes, autoria, credibilidade, profundidade da informação, atualização <.org/.gov/.com/.net/.edu>;

- Identificar as estratégias bem sucedidas para fundamentar buscas futuras . 
Para a pesquisa na Internet, vale a pena considerar também alguns lembretes em torno da palavra "busca" (Adaptado de EAGLETON; GUINEE, 2002, apud HENRY, 2006):

- Busque um propósito para pesquisar;

- Use estratégias de pesquisa efetivas;

- Saiba analisar resultados;

- Critique os resultados e sintetize as informações;

- Apresente suas fontes de pesquisa (endereço/data de acesso).

Estratégias de Pesquisa, conforme EAGLETON; GUINEE, (2002, apud HENRY, 2006), 'Seja...':

- Específico: delimite, estreite o foco de busca;

- Exato: use palavras ou a frase que espera encontrar;

- Direto: pesquise um foco de cada vez e evite repetições;

- Conciso: use palavras-chave adequadas, elimine as que forem desnecessárias.

Assim, para que o estudante possa desenvolver habilidades de novos letramentos e as estratégias necessárias para acessar informação na Internet com êxito, é preciso dispor de uma abordagem instrucional adequada para pesquisa de informação e praticá-la na escola.

Fechamos essa reflexão aplicada projetando-a no plano educacional. Fazemos nossas as idéias de dois pensadores de expressão no debate sobre o impacto das novas tecnologias nas relações humanas e na cultura contemporânea:

Si hay tecnología informática generalizada y si hay Internet, la escuela no será igual. (CASTELLS, 2008)

Para pensar la educación del futuro, los impedimentos de hoy no son obstáculos tecnológicos sino impedimentos de la imaginación. (BURBULES, 2007) 


\section{REFERÊNCIAS}

BERNARDES, A. S.; FERNANDES, O. P. A pesquisa escolar em tempos de Internet. In: FREITAS, M. T. A.; COSTA, S. R. (Orgs.). Leitura e escrita de adolescentes na internet e na escola. Belo Horizonte: Autêntica, 2005, p. 117-136.

BURBULES, N. Diálogos en Educación - entrevista con Nicholas Burbules. Disponível em: <http://www.educared.org.ar/biblioteca/ dialogos/entrevistas/entrevista_nicholas_burbules.asp>. Acesso em: ago. 2007.

CASTELLS, M. Docentes reciclados - entrevista com Manuel Castells. 2008. Disponível em: <http://docentesreciclados.blogspot.com/2008/08/si-haytecnologa-informtica.html>. Acesso em agosto de 2007.

ECO, U. O Dilúvio da informação (VEJA - Vida Digital). VEJA, ano 33, n. 52, p. $11-15,04 / 12 / 2000$.

HENRY, L. A. Searching for an answer: the critical role of new literacies while reading on the Internet. The reading teacher, v. 59, n. 7, p. 614-627, April 2006.

JUNGWIRTH, B.; BRUCE, B. C. Information overload: threat or opportunity? Journal of adolescent $\&$ adult literacy: navigatin new literacies, v. 45 , n. 5 , February 2002.

PORTAL EducaRede - < http://www.educarede.org.br $>$. Portal EducaRede, Fórum. Disponível em: < http:www.educarede.org.ar/aua/2007/intercambio/>. Acesso em: 23 ago. 2007.

VIEIRA, I. L. Leitura na Internet: Mudanças no perfil do leitor e desafios escolares. In: ARAÚJO, J. C. (Org). Internet \& ensino: novos gêneros, outros desafios. Rio de Janeiro, Lucerna, 2007a. p. 244-267.

Letramento digital e leitura na web: como anda a aplicação escolar? (Trabalho apresentado em VIII Congresso Brasileiro de Linguística Aplicada ALAB, Brasília, 9 a 11 de julho 2007b.)

\section{ANEXO 1}

1. Forum - Internet na Escola (acesso 07-10-09):

VIEIRA - A busca de informação na web... 
Tema livre

Este é um espaço democrático para expressão de ideias que não traduzem necessariamente a opinião do Portal.

Vamos avançar no nosso debate sobre a entrega de uma lista de sites aos alunos e pensar nas seguintes questões:

E depois da lista? Eles saberão aventurar-se sozinhos no ciberespaço?Como o professor pode desenvolver as habilidades de pesquisa de seus alunos? Ou o professor será um eterno filtro entre o aluno e a Internet? Publique sua opinião e/ou responda a dos colegas.

Esta discussão é mediada por Marcia Padilha, especialista em Educação e Tecnologia. Textos de apoio

Parte superior do formulário

\section{Fórum: Internet na Escola}

Conheça a mediadora deste fórum

Marcia Padilha é mestre em História e foi uma das responsáveis pela concepção do Programa EducaRede no Brasil, atuando como coordenadora do Programa por quatro anos. Trabalha como formadora de jovens e de educadores, editora e autora de materiais educacionais há mais de dez anos. Desde 2000, dedica-se a projetos de uso educativo da Internet e de outras mídias, à elaboração de cursos a distância e à colaboração de ONGs como Midiativa e Rede Livre.

Parte inferior do formulário

\section{Ler texto}

Receber mensagens desse tema por e-mail?

Enviar nova mensagem

Lista de mensagens (alguns registros encontrados) 


\section{TíTULO}

Listagem de sites

planejamento

Será que estamos

preparados?

Prep ará odo cente

pode ser um $\mathrm{m}$...

Prep aração dos

professores

Prep arad os?aind a não.

Intem et na Escola

LISTA DE SITES PARA

PESQUISAS

\section{AUTOR}

Evanilza Neride Sous a

Palopoli

Angela Cardoso Brollo

William Anto nio

Zac ario tto

marimi carneiro da silva

Almir Roberto Ribeiro

Jacira Santo do Prado

Vasconcellos

Umbelina Barreto

Teresinha Sanches
RESP.

DATA

0

15/09/2007 - 11:02

0

$14 / 09 / 2007-07: 23$

3

14/09/2007 - 01:51

14/09/2007 - 03:24

15/09/2007 - 12:31

$15 / 09 / 2007-07: 40$

0

$14 / 09 / 2007-11: 07$

2

$14 / 09 / 2007-10: 40$

\section{Acessando o fórum como dados de pesquisa: Ordenando as mensagens}

\section{Mensagem 1 de 3}

Sobre planejamento x Orkut e MSN 3

Enviada em 08/09/2007 - 10:23

Muito bem!

Aula preparada, foco no assunto, exposição prévia do tema com abordagem do assunto pela fala.

Realidade: 10 Pcs para 40 alunos, alunos que são familiarizados como mundo da informática e alunos que não sabem ao menos ligar os Pcs.

Alunos expertes em informática que dão um jeitinho de entrar em Orkut e msn e o professor perde tempo, que já é escasso, para botar ordem acabando por não atingir seu objetivo.

Que fazer?

Amarildo Ap. Pereira Ferreira

amarildoapfilosofia@hotmail.com

\section{Responder mensagem}

\section{Mensagem 1 de 3}

Sobre indicação de sites

Enviada em 08/09/2007 - 19:29

Acredito que se o educador apresentar ao aluno sites interessantes, ele usará e recomendará para colegas. Daí a importância de uma boa seleção.

\footnotetext{
${ }^{3} \mathrm{O}$ foco das mensagens, escrito em letra cinza foi inserido pela pesquisadora (para acompanhar o teor da discussão) e não pelos participants do Fórum EducaRede.
}

VIEIRA - A busca de informação na web... 
Kátia Socorro Motta Melo

katia.historia@yahoo.com.br

\section{Responder mensagem}

\section{Mensagem 2 de 3}

Sobre indicação de sites

Enviada em 10/09/2007 - 15:23

Concordo com vc qdo diz da necessidade de apresentarmos uma listagem da sites qdo solicitamos uma pesquisa na net. Afinal, qdo direcionamos o aluno a buscar aquilo que solicitamos há como ele responder de forma orientada; outrossim, podemos sugerir q ele busque outras alternativas, pois não deve ficar "engessado". Qto ao professor que questionou sobre msn e orkut, sugiro que haja uma conversa para se definir espaços e parâmetros. Embora façamos um trabalho de formiguinhas, cabe a nós esclarecermos aos alunos que há hora e lugar para tudo... e se estamos em meio a uma aula não é o momento de verificarmos mensagens. Entretanto, ainda podemos usar o Orkut como espaço para publicação de trabalhos dos alunos.

Rachel

rachel aparecida dos santos

rachelsantos10@gmail.com

\section{Responder mensagem}

\section{Mensagem 2 de 3}

Sobre "Planejamento Rizomático"

Enviada em 10/09/2007 - 16:26

Se planejamos com objetivos lineares ou sequências, o trabalho com o grupo fica quebrado, por isso a flexibilidade da aula é muito importante, procure fazer um planejamento rizomático, onde todo esses problemas, podem toranar-se ajuda na construção do conhecimento dos participantwe do grupo. não haverá perda de tempo, e o objetivo não deve ser do professor e sim do coletivo.

Gilvando Araujo de Brito

gilvandobrito@yahoo.com.br

\section{Mensagem 3 de 3}

Sobre objetivo

Enviada em 11/09/2007 - 14:17

Gostaria de saber o que você quer dizer com objetivo do coletivo.

Selma regina de Oliveira

selma regina de oliveira

selma@netstyle.com.br

\section{Responder mensagem}

\section{Mensagem 3 de 3}

Sobre seleção de sites

Enviada em 11/09/2007 - 14:19

Concordo, ele realmente usará e recomendará. Mas temos que levar em consideração que o que é interessante para alguns não é interessante para outros. E ainda temos todos os 
outros atrativos, que para os alunos são mais interessantes do que os sites aprsentados pelo professor.Garotos se interessão muito mais por sites que tenham jogos de guerra, do que sites que digamos sejam educacionais.

Sandra Brun Beteto

menininha_sbbb@hotmail.com

Responder mensagem

Mensagem 1 de 1

Salas de bate papo entre alunos e professores

Enviada em 11/09/2007 - 11:25

A internet na escola, teriam como incentivo salas de bate papo entre alunos e professores para compartilhamento de conhecimento onde alunos encontrariam um meio mais rápido para tirar dúvidas e adquirir mais conhecimento.

Andreza Pereira Nascimento de Souza

andreza_sou_z@hotmail.com

\section{Mensagem 1 de 4}

sobre bate-papo

Enviada em 11/09/2007 - 11:28

Muitos alunos estão nessa de bate-papo e muitas vezes e muito perigoso por conter

conteúdos inadequados, o que vocês acham?

Karla Roberta do Nascimento Silva

carla_cat_sa@yahoo.com.br

\section{Mensagem 2 de 4}

NEM TODOS LEVAM A SÉRIO... (título do autor da mensagem)

Enviada em 11/09/2007 - 14:22

HÁ MUITO TEMPO ATRÁS JÁ PODE TER SIDO BOM, MAS HOJE EM DIA VEJO QUE O BATE PAPO NÃO É INTERESSANTE, POIS AS PESSOAS NÃO ESTÃO MAIS LEVANDO A SÉRIO.....NO ENTANTO JA VI MUITAS PESSOAS QUE ACABAM SAINDO MACHUCADAS DEPOIS.

MARIA ALICE DOS SANTOS DOCA

ALICE_DOCA@HOTMAIL.COM

\section{Mensagem 1 de 1}

Sobre o suporte

Enviada em 11/09/2007 - 19:49

No meu ponto de vista, o professor deve indicar sites de pesquisa aos alunos e incentiválos a buscar mais conhecimentos em outros sites também, não se predendo a opinião de apenas um. No entanto, o professor deve estar atento as dívidas que possam surgir e "cobrar" algum conhecimento de pesquisa durante a confecção do trabalho, sendo um suporte de auxílio para que os alunos possam interagir com a questão abordada, fazendo com que desperte o interesse pelas pesquisas.

Joselma Lucindo da Silva josi.lucindo@terra.com.br

\section{Responder mensagem}

VIEIRA - A busca de informação na web... 


\section{Mensagem 1 de 1}

Sobre entrega de lista de sites

Enviada em 13/09/2007 - 19:01

Primeiro tenho de ver se compreendi bem: A pergunta é se entregarmos uma lista de sites aos educandos como deveremos proceder? como mediador, orientando e controlando?

Bom, vamos por partes. A Internet oferece um conteúdo informativo excessivo, ao tempo que há esta oferta muitos deles carecem de qualidade e até mesmo de veracidade. Portanto, seguindo por essa ressalva faz-se necessário diante uma pesquisa solicitada aos educandos promover sim uma filtragem, nesse aspecto somos mediadores. Por outro lado entregar uma "lista" e não proceder mecanismos que levem a necessidade de ir buscar a informação e transformá-la em conhecimento é que pode dar errado no trabalho a ser desenvolvido, então além de mediador deveremos ser o educador que provoca, que desestabiliza, que tira o educando da zona de conforto, de sua equilibração e leva-o a um novo ponto - para equilibrar-se o mesmo deverá pesquisar, isso não quer dizer que estamos afunilando o conhecimento e fazendo com os educandos ou educandas venham a pensar com o orientador, mediador e sim que fora entregue as ferramentas que irão possibilitar uma aprendizagem significativa.

Eudes Gurgel eudesgurgel@digi.com.br

\section{Mensagem 3 de 4}

Sobre bate papo

Enviada em 14/09/2007 - 10:31

Como professora de Língua Portuguesa, valorizo a comunicação e a sala de bate-papo é um instrumento interessante, quando orietado e fiscalizado, pois permite que o educando se expresse com raciocínio rápido e significativo

Maria Gorett Rufino de Almeida

gorettbaby_19@hotmail.com

\section{Mensagem 1 de 3}

Sobre lista de sites para pesquisas

Enviada em 14/09/2007 - 10:40

Os profesores devem atuar como mediadores,orientando os alunos'para que

desenvolvam habilidades e aprendam a navegar em sites seguros e a elaborar pesquisas.

Teresinha Sanches

tetesanches@uol.com.br

\section{Responder mensagem}

\section{Mensagem 4 de 4}

BATE-PAPO - caiu na vulgaridade (título dado pelo autor da mensagem)

Enviada em 14/09/2007 - 12:05

Em minha cidade alguns casamentos chegaram ao fim depois que um dos cônjuges descobriu que seu companheiro vivia trocando palavras, via orkut, com outra pessoa descasada. 


\section{6}

Concordo que a maioria levou o bate-papo para o lado vulgar. Fora isso, veja a ortografia usada. É uma aberração à nossa língua oficial. Daqui a pouco nem isso teremos mais. CIRINEU DA SILVA - cirimari@ig.com.br

\section{Mensagem 1 de 2}

Sobre salas de bate-papo

Enviada em 14/09/2007 - 00:13

Sobre as salas de bate papo é fundamental que pais e educadores estejam sempre orientando os educandos... Afinal, a internet deve ser usada de forma educativa e prazerosa! Elaine Oliveira - elaine_libriana75@yahoo.es

\section{ANEXO 2}

\section{Fórum: Internet na Escola (acesso em 7-10-07)}

http://www.educarede.org.br/educa/index.cfm?pg=forum.ds_listatopicos\&\&id_comuni dade=0\&ID_FORUM=188\&updateParticipante $=1$

\section{Tema livre}

Este é um espaço democrático para expressão de ideias que não traduzem necessariamente a opinião do Portal.

Vamos avançar no nosso debate sobre a entrega de uma lista de sites aos alunos e pensar nas seguintes questões:

E depois da lista? Eles saberão aventurar-se sozinhos no ciberespaço?Como o professor pode desenvolver as habilidades de pesquisa de seus alunos? Ou o professor será um eterno filtro entre o aluno e a Internet? Publique sua opinião e/ou responda a dos colegas.

Esta discussão é mediada por Marcia Padilha, especialista em Educação e Tecnologia.

Textos de apoio

\section{Ler texto}

Receber mensagens desse tema por e-mail?

\section{Enviar nova mensagem}

Lista de mensagens (alguns registros encontrados)

VIEIRA - A busca de informação na web... 
TíTULO

$\triangle$ Planejar a ação

Sobre o tema em questão

Avançar na educ ação

digital é ...

Esta min ha participação

é graç...

RESPOSTA

INTERNET NA

ESCOLA

Pesquisa do educando

Filtro

Recurso educ ativo

Mire um po nto no

horizonte..

\section{AUTOR}

Rosalva Teixeira Barro

Antonia Lucelia Santos

Mariano

Antonia Lucelia Santos

Mariano

Joana de Jesus

Goncalves

Rita de Cássia Lima de

Sousa

Rita de Cássia Lima de

Sousa

jonas salles desouza $\quad 0$

jonas salles desouza 1

Zilmara Seabra Borges 0

Christian Messias

Menese s Soares

0

0

(1)
RESP.

DATA

0

06/ 10/2007 - 11:47

03/ 10/2007 - 06:37

1

03/ 10/2007- 06:28

0

$06 / 10 / 2007-11: 27$

0

03/ 10/2007 - 11:13

03/10/2007 - 10:51

03/ 10/2007 - 10:49

$03 / 10 / 2007-10: 45$

$03 / 10 / 2007-10: 56$

6

03/ 10/2007 - 10:26

Acessando o fórum como dados de pesquisa: Ordenando as mensagens.

Fórum: Internet na Escola

Navegação entre mensagens

Este é um espaço democrático para expressão de ideias que não traduzem

necessariamente a opinião do Portal.

Responder mensagem

Resposta seguinte $>$

\section{Mensagem 1 de 2}

Qual deve ser a postura do professor diante dos recursos tecnológicos que tem hoje na sua formação?

Enviada em 01/10/2007 - 10:49

Bom pessoal,

A formação é sem dúvida um item esencial para transformação da prática docente, isso por que na educação cada dia as coisas transformam-se inovam-se e temos que acompanhar isso como eternos desbravadores do saber e os recursos tecnológicos são uma grande ferramenta para isso. Além disso nossos alunos estão em constante contato com esse mundo e nós temos que acompanhá-los para que possamos atender seus anseios e promover uma aprendizagem significativa...

Adriana Aparecida Silveira Honório

educ.coordenadoria@lencoispaulsita.sp.gov.br 


\section{8}

\section{Responder mensagem \\ $<$ Resposta anterior}

\section{Mensagem 2 de 2}

Postura do Professor

Enviada em 01/10/2007 - 14:23

Olá Adriana,

Concordo com suas palavras, pois tento desafiar todas as inovações que surgem para um avanço dos nossos educandos, procuro conservar o que é bom e somar tudo o que é bom "do novo".Nossos educandos exigem de nos cada vez mais sendo assim temos que captar essas inovações em ritmo acelerado.

Meu abraço

MARIA THEREZA FERNANDES BORGES

therezaborges@yahoo.com.br

Mensagem 1 de 3

Crianças a mercê de si mesmas.

Enviada em 01/10/2007 - 10:50

A cada dia, nos deparamos com familias em que os filhos ( de 6 a 10 anos) decidem o que devem e podem fazer. Os pais não conseguem ou não sabem que são imaturos ainda para tomarem decisões que dizem respeito ao futuro deles.

Se uma bola ultrapassa os muros da escola, podemos esquecer da possibilidade de encontrá-la. Crianças ou adolescentes a encontram, e em vez de devolverem levam para casa. A maioria dos pais aceitam que tenham uma bola ou qualquer outro objeto que não foi comprado por eles. Normal. Como devemos agir?

A escola deve, enquanto a criança permanece dentro dela, ensinar valores e cobrar atitudes? Ou devemos culpar os pais que não ensinam?

Neusa Maria Carone

neusa.carone@uol.com.br

\section{Responder mensagem}

O papel dos educadores

Enviada em 02/10/2007 - 19:28

Sem dúvida acredito que o papel do educador inclui ensinar valores, uma vez que nem todos os pais estão preocupados com isso, e muitas vezes confudem LIBERDADE com LIBERTINAGEM, daí o resultado que a nossa sociedade assiste, uma total desordem, onde o correto passa a ser incorreto e as pessoas tem vergonha de serem honestas ou mesmo educadas perante a um publico que não valoriza certos gestos que para mim jamais caem de moda, como por exemplo dizer muito obrigada, com licença ou por favor.(isso para falar das coisas mais básicas).

Kátia Socorro Motta Melo

katia.historia@yahoo.com.br

\section{Responder mensagem}

\section{Mensagem 3 de 3}

Crianças a mercê de si mesma.

VIEIRA - A busca de informação na web... 
Enviada em 03/10/2007 - 10:20

A escola é um espaço onde este e outros temas podem ser trabalhados. Entretanto é necessário que a familia discuta com os filhos a respeito desse comportamento de pegar coisas que não são suas. É de responsabilidade dos pais acompanharem seus filhos e questionar onde encontraram, quem ofereceu, por que. Só assim os pais poderam evitar que os filhos cheguem em casa com drogas, coisas roubadas e até mesmo armas.

Raimundo Nonato Oliveira de Sousa

nonatogeo10@yahoo.com.br

\section{Responder mensagem}

\section{Mensagem 1 de 1}

Língua escrita

Enviada em 01/10/2007 - 10:50

Para trabalhar com a língua escrita, preciso ser um usuário dinâmico dela, caso contrário não terei condições de desenvolver os procedimentos de escritor e menos ainda de mostrar o caminho para os alunos. Planejamento, textualização, revisão e edição, são as etapas para se produzir qualquer texto, claro que alguns gêneros demandam mais atenção e tempo, aqueles mais informais. Quanto tempo estou investindo no ensino da língua escrita e no uso significativo dela?

Rosangela Cristina Morelli

crismorelli@hotmail.com

\section{Responder mensagem}

\section{Mensagem 4 de 4}

Internet na Educação

Enviada em 03/10/2007 - 10:39

falta-nos o preparo adequado para os desfios de enfrentarmos às nova tecnologias, pois os dirigentes colocados a frente dos orgãos de educação pública, na maioria das vezes estão tão distanciados da realidade dos profissionais que se esquecem de sem sálarios nos não estaremos capacitado às minhas mudanças, pois não temos como assimilarmos pretenças mudanças de pradigmas e ou culminâncias sociais.

Pedro da Sillva Coutinho peterkowtynnho@yahoo.com.br

\section{Responder mensagem}

\section{Mensagem 3 de 4}

Fórum: Internet na Escola

Enviada em 03/10/2007 - 10:18

Falta-nos o principal, o preparo para as novas tenologias, de maneira transparente por parte dos adms públicos, quando colocam à frente dos orgãos de educação pessoas distanciadas das realidades vivenciadas pelos educadores escolares das redes públicas, sejam elas municipais, estaduais ou federais.

kowtynnho

Pedro da Sillva Coutinho peterkowtynnho@yahoo.com.br

\section{Responder mensagem}




\section{Mensagem 2 de 4}

RESP.; O QUE SEREMOS DAQUI PARA A FRENTE

Enviada em 02/10/2007 - 16:21

$\mathrm{Na}$ verdade devemos estar procurando melhorar o nosso potencial. Não há mais lugar para parasitas. $\mathrm{O}$ profissional deve estar atento as mudanças. $\mathrm{O}$ aluno não aceita a mesmice, nem o faz de conta. Muitos não sabem dizer o que querem, mas também não aceitam qualquer coisa. Daí ocorre a evasão, a desistência e até a reprovação. É uma resposta, muitas vezes, a falta de preparo de muitos profissionais da educação.

Maria Martinelia Inacio de Oliveira Bezerra

martiinacio@hotmail.com

\section{Responder mensagem}

\section{Mensagem 1 de 4}

O que seremos daqui para frente Enviada em 02/10/2007 - 13:57

Acretito que a coisa toda só vai dar certo se todos estivermos interligados na rede. Vi a reportagem do Fantastico daquela escola na favela onde a internet tornou-se ferramenta para os estudantes. $\mathrm{Na}$ educação se não houver um orientador o estudo tende a cair em pensamentos errados, ou seja, ao invés de aprender o aprendiz pode emburrecer mesmo tendo a tecnologia ao seu favor! A figura do professor é estritamente necessária para que o conhecimento trace caminhos certos.

Claire Dali da Silva

clairedalisilva@yahoo.com.br

\section{Responder mensagem}

\section{Mensagem 3 de 3}

A internet é uma ferramenta de grande utilidade na escola!

Enviada em 06/10/2007 - 11:43

A internet é uma ferramenta de grande utilidade na escola mesmo.

E que os educadores têm que se aperfeiçoarem nesta modalidade de tecnologia para não se tornarem obsoletos. É mais uma realidade que deve ser encarada.

Joana de Jesus Goncalves

joanaouro@yahoo.com.br

\section{Responder mensagem}

\section{Mensagem 2 de 3}

Planejar sempre...

Enviada em 03/10/2007 - 10:51

Será que nossas escolas atualmente já tem condições de inserir a tecnologia e o uso da internet no seu projeto pedagógco?

Começar a discussão deste tema e muito importante, e poder contar com o apoio de todos os setores da escola também.

Há sempre um primeiro passo...

Christian Messias Meneses Soares

emmac.teresina@gmail.com

VIEIRA - A busca de informação na web... 


\section{Responder mensagem}

\section{Mensagem 1 de 3}

A internet na escola

Enviada em 03/10/2007 - 10:11

Bom dia, Marcia Padilha.

A internet é uma ferramenta de grande utilidade na escola. Eu acredito que não tem mais volta, os educadores têm que se aperfeiçoar nesta modalidade de tecnologia para não se tornar obsolet.

Usar a internet por usar não caracteriza um estudo pedagógico, por isso, o professor tem que ter seu planejamento com os objetivos a serem atinjidos por ele e seus alunos para que a aprendizagem prevista realmente aconteça.

Francisco Ivan Assis de Araújo

Frabcisco Ivan Assis de Araújo

ivan.araujof@yahoo.com.br

\section{Responder mensagem}

\section{Mensagem 3 de 3}

Dicas para o aluno não perder o foco da pesquisa

Enviada em 06/10/2007 - 11:35

concordo com o professor josé que, a orientação do professor para o aluno não perder o foco da pesquisa, dando susjestões e dicas para que a pesquisa vá de encontro ao tema proposto seja um ponto de partida para toda e qualquer pesquisa interativa. E que em um outro momento haja a verificação do resultado da pesquisa se foi ou não, satisfatório.

Joana de Jesus Goncalves

joanaouro@yahoo.com.br

\section{Responder mensagem}

\section{Mensagem 2 de 3}

Um remo precioso...

Enviada em 03/10/2007 - 10:42

Assim como o remo tem ser de material resistente, leve e ao mesmo tempo firme, o uso da internet também precisa ser bem estruturado na sua elaboração e uso, permitindo que todos ganhar com a pesquisa e de fato aprender.

Muito boa a colocação.

Christian Messias Meneses Soares

emmac.teresina@gmail.com

\section{Responder mensagem}

\section{Mensagem 1 de 3}

Orientação

Enviada em 03/10/2007 - 10:23

Imaginem você em um barco sem remo. Situação similar é um aluno que acessa a iternert para fazer uma pesquisa escolar(mesmo com o tema definido). Pode aconter que no momento da pesquisa desviar-se por outros caminhos que lhe chame a atenção por algum motivo. 
Aí, entre a orientação do professor para o aluno não perder o foco da pesquisa, dando susjestões e dicas para que a pesquisa vá de encontro ao tema proposto. Em outro momento verificar o resultado da pesquisa foi satisfatório.

José Lindomar da Costa Santos

JOSÉ LINDOMAR DA COSTA SANTOS

ELDERLINDOMAR@YAHOO.COM.BR

Responder mensagem

\section{Mensagem 6 de 6}

A figura do professor

Enviada em 06/10/2007 - 23:56

Zilmara, por isso é tão importante a figura do professor. É ele que deverá transformar informação em conhecimento, através de ações bem planejadas e com objetivos bem definidos.

Rosalva (rosalvabarro@uol.com.br)

Rosalva Teixeira Barro

rosalvabarro@uol.com.br

\section{Responder mensagem}

\section{Mensagem 4 de 6}

Internet na Escola

Enviada em 03/10/2007 - 10:50

Não é só lixo cultural que transferido para a população desinformada, são as

cosequências que estas desinformação provocam em mentes tão carentes de informações, cidadania, amor fraternal familiar e outros requisitos sociais.

peterkowtynnho@yahoo.com.br

Pedro da Sillva Coutinho

peterkowtynnho@yahoo.com.br

\section{Responder mensagem}

Fala sério

Enviada em 03/10/2007 - 11:03

Considera-se lixo cultural sites pornogáficos ,fofocas, resumos de novelas entretanto a pesquisas não envolvem reflexões acerca de fatos de relevância como politica,economia,educação, saúde entre outros.

Zilmara Seabra Borges

zil.seabra@yahoo.com.br

\section{Responder mensagem}

\section{Mensagem 3 de 6}

Lixo cultural

Enviada em 03/10/2007 - 10:49

O que quis dizer " com os sites acessados segundo pesquisas limitam-se ao que se denomina "lixo cultural.""?

JOSÉ LINDOMAR DA COSTA SANTOS

ELDERLINDOMAR@YAHOO

VIEIRA - A busca de informação na web... 


\section{Responder mensagem}

Internet é um caminho.

Enviada em 03/10/2007 - 10:37

A popularização da tecnologia tanto trás inovações no campo das informações como revela uma lacuna existente entre o mundo real e o virtual.

Como podemos evoluir tecnologicamente, se o preço dessa evolução está nos milhoes brasileiros que não tem sequer as condições míninas de sobrevivência. Dados estes que você pode consultar pela internet, mas não pode resolver pela mesma.

Christian Messias Meneses Soares

emmac.teresina@gmail.com

\section{Responder mensagem}

(Obs: a mensagem seguinte é um tanto radical...)

\section{Mensagem 1 de 6}

Afinal internet construção de conhecimentos ou transmissão de informações?

Enviada em 03/10/2007 - 10:25

A era tecnológica chegou... Mas afinal a tecnologia é de fato um divisor de águas entre aqueles que possuem condiçoes de se beneficiar do aparato tecnológico tendo em vista que a simples popularização do aparelho de celular na significa uma inclusão digital já que a grande maioria dos usuários se quer sabem enviar uma mensagem de texto de acordo com dados recentes, portanto a ampliação do número de usuários na internet reflete apenas em grande parte disponibilização de informações, considerando-se que os sites acessados segundo pesquisas limitam-se ao que se denomina "lixo cultural."

Zilmara Seabra Borges

zil.seabra@yahoo.com.br

\section{Responder mensagem}

\section{Levantamento de ideias trocadas no fórum observado no portal EducaRede (realizado pela pesquisadora)}

Fórum: Internet na Escola

\section{Tema livre}

Este é um espaço democrático para expressão de ideias que não traduzem necessariamente a opinião do Portal.

Vamos avançar no nosso debate sobre a entrega de uma lista de sites aos alunos e pensar nas seguintes questões: E depois da lista? Eles saberão aventurar-se sozinhos no ciberespaço? Como o professor pode desenvolver as habilidades de pesquisa de seus alunos? Ou o professor será um eterno filtro entre o aluno e a Internet? Publique sua opinião e/ou responda a dos colegas.

Esta discussão é mediada por Marcia Padilha, especialista em Educação e Tecnologia. 


\section{ANEXO 3}

\section{Listagem resumida das ideias discutidas no fórum (elaborada pela pesquisadora)}

1. Indicação de sites interessantes quando se propõe pesquisa na Internet listagem.

2. Planejamento rizomático - flexibilidade da aula, objetivos coletivos.

3. Objetivos interessantes para o professor podem não ser para o aluno.

4. Incentivar alunos a procurar outros sites, ampliando os fornecidos por ele, ficando atento à dúvidas, cobrando algum conhecimento de pesquisa, sendo suporte e auxílio, despertando interesse pelas pesquisas.

5. Papel do professor: A pergunta é se entregarmos uma lista de sites aos educandos como deveremos proceder? como mediador, orientando e controlando?

1. R: filtrar $=$ mediador + provocador, tirar o aluno da zona de estabilidade

6. Os professores devem atuar como mediadores, orientando os alunos para que desenvolvam habilidades e aprendam a navegar em sites seguros e a elaborar pesquisas.

7. A formação do professor acompanhando as inovações tecnológicas.

8. O papel do educador inclui ensinar valores.

9. Falta-nos o preparo adequado para os desafios de enfrentarmos as nova tecnologias, pois os dirigentes colocados a frente dos órgãos de educação pública, na maioria das vezes estão tão distanciados da realidade dos profissionais.

10. Falta-nos o principal, o preparo para as novas tecnologias, de maneira transparente por parte dos administradores públicos, quando colocam à frente dos órgãos de educação pessoas distanciadas das realidades vivenciadas pelos educadores escolares das redes públicas, sejam elas municipais, estaduais ou federais.

11. Na verdade devemos estar procurando melhorar o nosso potencial. Não há mais lugar para parasitas.

12. O que seremos daqui para frente - Acredito que a coisa toda só vai dar certo se todos estivermos interligados na rede. Vi a reportagem do Fantástico daquela escola na favela onde a internet tornou-se ferramenta para os estudantes. $\mathrm{Na}$ educação se não houver um orientador o estudo tende a cair em pensamentos errados, ou seja, ao invés de aprender o aprendiz pode emburrecer mesmo tendo a tecnologia ao seu favor! A figura do professor é estritamente necessária para que o conhecimento trace caminhos certos.

13. A internet é uma ferramenta de grande utilidade na escola mesmo. E que os educadores têm que se aperfeiçoarem nesta modalidade de tecnologia para não se tornarem obsoletos. É mais uma realidade que deve ser encarada.

14. Será que nossas escolas atualmente já têm condições de inserir a tecnologia e o uso da internet no seu projeto pedagógico? 
15. A internet é uma ferramenta de grande utilidade na escola. Eu acredito que não tem mais volta, os educadores têm que se aperfeiçoar nesta modalidade de tecnologia para não se tornar obsoleta. Usar a internet por usar não caracteriza um estudo pedagógico, por isso, o professor tem que ter seu planejamento com os objetivos a serem atingidos por ele e seus alunos para que a aprendizagem prevista realmente aconteça.

16. Dicas para o aluno não perder o foco da pesquisa (enviada em 06/10/2007 11h35minh)

2. Concordo com o professor José que, a orientação do professor para o aluno não perder o foco da pesquisa, dando sugestões e dicas para que a pesquisa vá de encontro ao tema proposto seja um ponto de partida para toda e qualquer pesquisa interativa. $\mathrm{E}$ que em um outro momento haja a verificação do resultado da pesquisa se foi ou não, satisfatório.

17. “Um remo precioso"... (colocação muito boa, enviada em 03/10/2007 10h42min): "Assim como o remo tem ser de material resistente, leve e ao mesmo tempo firme, o uso da internet também precisa ser bem estruturado na sua elaboração e uso, permitindo que todos ganhar com a pesquisa e de fato aprender."

18. "Imaginem você em um barco sem remo. Situação similar é um aluno que acessa a internet para fazer uma pesquisa escolar (mesmo com o tema definido). Pode acontecer que no momento da pesquisa desviar-se por outros caminhos que lhe chame a atenção por algum motivo. Aí, entre a orientação do professor para o aluno não perder o foco da pesquisa, dando sugestões e dicas para que a pesquisa vá de encontro ao tema proposto. Em outro momento verificar o resultado da pesquisa foi satisfatório."

19. A importância da figura do professor. É ele que deverá transformar informação em conhecimento, através de ações bem planejadas e com objetivos bem definidos.

20. Considera-se lixo cultural sites pornográficos, fofocas, resumos de novelas, entretanto a pesquisas não envolvem reflexões acerca de fatos de relevância como política, economia, educação, saúde entre outros.

21. O que quis dizer "com os sites acessados segundo pesquisas limitam-se ao que se denomina 'lixo cultural."?

22. "Internet é um caminho" (enviada em 03/10/2007 - 10h37min)

3. A popularização da tecnologia tanto trás inovações no campo das informações como revela uma lacuna existente entre o mundo real e o virtual.

4. Como podemos evoluir tecnologicamente, se o preço dessa evolução está nos milhões brasileiros que não tem sequer as condições míninas de sobrevivência. Dados estes que você pode consultar pela internet, mas não pode resolver pela mesma.

23. Inclusão digital... Afinal internet é construção de conhecimentos ou transmissão de informações? A era tecnológica chegou... Mas afinal a tecnologia é de fato um divisor de águas entre aqueles que possuem condições de se beneficiar do aparato tecnológico tendo em vista que a simples popularização do aparelho de celular na significa uma inclusão digital já que a grande maioria dos usuários se quer sabem enviar uma mensagem de texto de 
acordo com dados recentes, portanto a ampliação do número de usuários na internet reflete apenas em grande parte disponibilização de informações [...]

Recebido em 25/01/09. Aprovado em 11/07/09.

Title: Searching for information on the web: from readers' problems to teaching practices

Author: Iúta Lerche Vieira

Abstract: This essay discusses the process of searching for information, the main type of web reading, based on data from a broader survey (VIEIRA, 2007/a) analyzed here from the viewpoints of the reader and the school. The discussion is carried out in the context of the information boom caused by the Internet and of the corresponding school challenges, since the search for information has always been a neglected issue within school environments. Searching for information is analysed according to a typology of reading difficulties on the Web. The data analysis reveals a great discrepancy between the needs or practices of a virtual reader and the most usual teaching proposals, suggesting that, although searching for information on the web is the major problem readers face, it is the the least focused on and performed reading activity at school. Finally, this article questions the way through which searching on the web can be taught, and some strategies are suggested.

Keywords: digital literacy; reading on the Web; search for information; critical reading; school survey.

Titre: La recherche de l'information sur le web: dès les problèmes du lecteur aux pratiques d'enseignement

Auteur: Iúta Lerche Vieira

Résumé: Cet essai discute la recherche d'information comme genre préférentiel de lecture sur le Web, à partir de données d'une recherche plus large (VIEIRA, 2007/a), ici analysés sous l'angle du lecteur et de l'application écolière. La discussion se situe dans le contexte de l'explosion informative déclenchée par Internet et des défis de l'école, où la recherche d'informations a toujours été un problème sans solution. La recherche d'information est vue selon une typologie de difficultés de lecture sur le Web. Les données analysées dévoilent une grande divergence parmi les besoins ou pratiques du lecteur virtuel et les propositions d'enseignement plus fréquents, démontrant que, bien que la recherche informative dans le réseau soit le plus grand problème des lecteurs, à l'inverse c'est l'activité lectrice moins focalisée et travaillée à l'école. Enfin, on se demande comment on pourrait enseigner à rechercher l'information sur Internet, en montrant quelques strategies.

Mots-clés: alphabétisation digitale; lecture sur Internet; recherche d'information; lecture critique; recherche écolière.

Título: La búsqueda de información en la Web: de los problemas del lector a las prácticas de enseñanza

VIEIRA - A busca de informação na web... 
Autor: Iúta Lerche Vieira

Resumen: El ensayo discute la búsqueda de información, tipo preferencial de lectura en la Web, a partir de datos de una pesquisa más amplia (VIEIRA, 2007/a), aquí analizados bajo el ángulo del lector y de la aplicación escolar. La discusión se sitúa en el contexto de la explosión informativa provocada por la Internet y de los desafíos de la escuela, donde la pesquisa de informaciones siempre fue un problema mal resuelto. La búsqueda de información es vista de acuerdo con una tipología de dificultades de lectura en la Web. Los datos analizados revelan una gran divergencia entre las necesidades o prácticas del lector virtual y las propuestas de enseñanza más frecuentes, mostrando que, aunque la pesquisa informativa en la red constituya el mayor problema de los lectores, inversamente es la actividad lectora menos focalizada y trabajada en la escuela. Por fin, se cuestiona el modo como se puede enseñar a buscar información en la Internet, apuntando algunas estratégias.

Palabras-clave: letramiento digital; lectura en la Internet; búsqueda de información; lectura crítica; investigación escolar. 